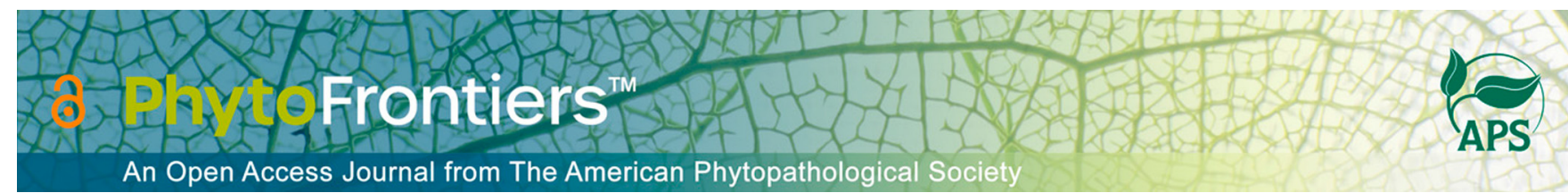

\title{
Research
}

\section{Mapping Quantitative Trait Loci for Lettuce Resistance to Verticillium dahliae Race 3, Plant Development, and Leaf Color Using an Ultra-High-Density Bin Map Constructed from $F_{2}$ Progeny}

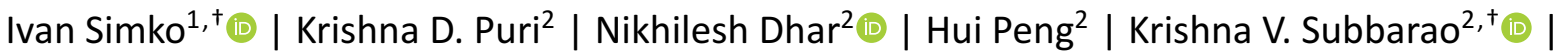

1 United States Department of Agriculture, Agricultural Research Service, Crop Improvement and Protection Research Unit, Salinas, CA 93905

2 Department of Plant Pathology, University of California, Davis, c/o U.S. Agricultural Research Station, Salinas, CA 93905

† Corresponding authors: I. Simko; ivan.simko@usda.gov, and K. V. Subbarao; kvsubbarao@ucdavis.edu

Accepted for publication 6 March 2022.

I. Simko and K. D. Puri contributed equally to this work.

Current address of K. D. Puri: Plant Industries Division, Missouri Department of Agriculture, Jefferson City, MO 65109, U.S.A.

The mention of trade names or commercial products is solely for providing specific information and does not intend and imply recommendation or endorsement by the USDA

\section{Funding}

This research was supported by grant numbers LGR-2020-09 and LGR-2021-13 from the California Leafy Greens Research Board to KVS. Funding for the project was also made possible by the U.S. Department of Agriculture's (USDA's) Agricultural Marketing Service through grant AM180100XXXXG003 to IS.

\section{Abstract}

Verticillium wilt is one of the most devastating soilborne diseases in lettuce, and the use of host resistance is the most optimal choice for its management. This study focused on identifying and mapping the genetic loci for resistance against Verticillium dahliae race 3 in a mapping population of $200 \mathrm{~F}_{2: 3}$ families developed from a cross between moderately resistant red-leaf lettuce 'Sentry' and susceptible green-leaf lettuce 'La Brillante'. The population was genotyped using the tunable genotyping-by-sequencing (tGBS) approach. An ultra-high-density genetic linkage map containing 34,838 single nucleotide polymorphism markers grouped into 1,734 bins was constructed using $F_{2}$ progeny and a sliding window approach Three quantitative trait loci (QTLs) for resistance to $V$. dahliae race 3 were located on linkage groups (LGs) LG 2 (qVR3-2.1) and LG 4 (qVR3-4.1 and qVR3-4.2). Each of these QTLs explained up to $\sim 10 \%$ of the total phenotypic variation for the trait. At each locus, the resistance alleles were derived from cultivar Sentry that is partially resistant to the pathogen. Additional loci resistant to the disease are expected in this population, and transgressive segregation indicates that some of those loci could originate from the susceptible cultivar La Brillante. In addition, two QTLs for plant development were identified on LG 2 (qIPD-2.1) and LG 7 ( $q I P D-7.1)$, although no relationship was detected between resistance in these genotypes and the rate of plant growth. A major effect of QTL for red leaf color was detected on LG 9 (qRLC-9.1). Candidate genes linked to some of the QTLs for $V$. dahliae race 3 resistance, plant development, and leaf color were identified. The QTLs for resistance identified in Sentry could diversify the resistance gene pool and provide an alternative tool to manage a newly emerged $V$. dahliae race 3.

Keywords: breeding, disease resistance, growth and development, inheritance, leaf color, lettuce, resistance loci, Verticillium wilt

The author(s) declare no conflict of interest. 
Verticillium wilt, caused by the soilborne fungus Verticillium dahliae, is an economically significant disease of many highvalue crops, including lettuce, tomato, artichoke, strawberry, and spinach in the Salinas and Pajaro Valleys of coastal Central California (Atallah et al. 2011; Subbarao et al. 2017) and many other hosts worldwide (Inderbitzin and Subbarao 2014; Klosterman et al. 2009; Ligoxigakis et al. 2002; Pegg and Brady 2002). Isolates of $V$. dahliae are classified as either race 1 or race 2 on tomato and lettuce (Fradin et al. 2009; Maruthachalam et al. 2010; Vallad et al. 2006). Most isolates recovered from affected lettuce fields in coastal California belong to race 1, with limited infestations of race 2 (Short et al. 2014). In 2017, however, race 3 on tomatoes was described in Japan (Usami et al. 2017). Based on the response of tomato rootstock cultivar 'Aibou' with resistance to both race 1 and race 2, Ingram et al. (2020) reclassified race 2 isolates from lettuce (VdLs17) and tomato (Le1811) as race 3, along with an additional isolate from tomato collected near Hollister, California, and eight isolates from North Carolina. Such reclassification contradicts the previously established race designation in lettuce based on the virulence patterns of isolates on lettuce differentials (Vallad et al. 2006).

Even though differential cultivar response-based race assignment in lettuce and tomato is the norm, the availability of molecular markers, including single nucleotide polymorphism (SNP) genetic markers (Short et al. 2014), has facilitated the identification of races among $V$. dahliae isolates from hosts in which either resistance or differential cultivars were unavailable. For example, isolates from artichoke, pepper, potato, spinach, and strawberry were classified as either race 1 or 2 using these markers (Short et al. 2014). Due to the unavailability of differential host cultivars to identify the presence of race 3 among $V$. dahliae populations from lettuce and other crops, we used molecular markers for avirulence genes developed from a comparative genomic analysis of three tomato isolates representing race 1 (JR2), race 2 (TO22), and race 3 (HoMCLT) (Wang et al. 2021). These avirulence genes from races 2 (Chavarro-Carrero et al. 2021) and 3 (VdAve3) were also functionally characterized to confirm that these were indeed avirulence genes. This race 3 marker was then used to classify isolates that had previously provided ambiguous results or to identify race 3 strains from newer collections of isolates (Wang et al. 2021). Kano and Usami (2019) elucidated that the race 3 isolate likely evolved from a race 1 divergence, although whole genome sequencing shows a distinct structural variation. One such isolate could not be classified as either race 1 or 2 previously, against which the race 1-resistant lettuce cultivars 'Sentry' and 'La Brillante' showed differential responses, and this was identified as race 3 using the race-specific marker and used in this study.

The resistance against race 1 in lettuce is conferred by a single dominant Verticillium resistance $1(V r l)$ locus initially identified on chromosomal linkage group (LG) 9 of the Batavia-type cultivar, La Brillante (Hayes et al. 2011b). The locus constitutes a complex cluster of four genes ( $\mathrm{LsVe} 1, \mathrm{LsVe} 2, \mathrm{LsVe} 3$, and $\mathrm{LsVe} 4$ ), where only a single allele, $L s$ VelL, present in the resistant cultivar La Brillante confers wilt resistance (Inderbitzin et al. 2019). The resistance exerted by the $V r l$ locus is stable under the field conditions despite high pathogen pressures (Puri et al. 2017). Several heirloom lettuce cultivars and breeding lines also carry resistance to V. dahliae race 1 (Hayes et al. 2007; Vallad et al. 2006) and are currently being incorporated into commercial cultivars (Hayes et al. 2011a, 2018). In tomato, the Ve R-gene locus encodes two leucine-rich repeat receptor-like proteins, Ve1 and Ve2, with Ve1 being the gene conferring resistance to $V$. dahliae race 1 (Nazar et al. 2018). The Ve homologs are widely distributed among crops such as cotton (Chen et al. 2016), potato (Simko et al. 2004;
Song et al. 2017), wild eggplant, hop (Song et al. 2017), mint (Vining and Davis 2009), sunflower (Fick and Zimmer 1974), and others, and the gene is considered to be of ancient origin.

Unlike race 1 resistance, complete resistance in lettuce against race 2 is unavailable, but several germplasm accessions with partial resistance have been identified (Hayes et al. 2011a, 2018; Sandoya et al. 2017). The genetics of partial race 2 resistance is complex. Analyzing three mapping populations from crosses involving Lactuca sativa $\times$ L. sativa and L. serriola $\times$ L. sativa, Sandoya et al. (2021) identified a common quantitative trait locus (QTL), qVERT6.1, on LG 6 and other race 2 resistance QTLs in several LGs. In contrast, resistance against race 2 in tomato is conferred by only a single locus (Stamova 2005; Usami et al. 2017). Usami et al. (2017) identified two tomato rootstocks, Aibou and 'Ganbarune-Karis', effective against race 2 that serve as cultivars to differentiate race 2 (nonpathogenic on Aibou) from race 3 (pathogenic on Aibou) in tomato.

A strong association between flowering time and plant defense has been reported in various plant pathosystems, including vascular wilt pathogens (Dhar et al. 2019; Lyons et al. 2015b; Ogawara et al. 2003; Singh et al. 2014). QTLs conferring resistance to Verticillium spp. Were mapped within the regions containing the flowering time gene in Arabidopsis thaliana (Haffner et al. 2010; Veronese et al. 2003). Plants respond to pathogens either by investing resources into immunity or by transitioning early into the reproductive phase, such as flowering and seed production, following a "growth versus defense conundrum" (Dhar et al. 2019; Huot et al. 2014; Lyons et al. 2015a). Lyons et al. (2015b) found a strong positive correlation between A. thaliana late flowering type and Fusarium wilt resistance. They further confirmed the upregulation of floral integrator genes or FLC, FT, and GI flowering loci following accelerated flowering in response to $F$. oxysporum infection. In contrast, the A. thaliana mutant $n d r 1-1$ that is highly susceptible to Verticillium spp. displays accelerated plant growth along with an early transition into flowering (Dhar et al. 2019, 2020a). Several hundred orthologs and paralogs of Arabidopsis flowering time genes are present in the lettuce genome, with 167 QTLs identified for bolting and flowering (Han et al. 2021). Thus, it is crucial to understand the association of these two traits in the lettuce- $V$. dahliae host pathosystem. A slight modification in harvesting time depending on disease incidence might be a strategy to rescue a crop from complete failure because the presence of $V$. dahliae in lettuce at the time of harvest does not alter the quality of harvested tissue during extended cold storage (Puri et al. 2019).

Anthocyanins are water-soluble, naturally occurring flavonoids that are responsible for color variation in leaves, flowers, and fruits in many plants, including lettuce (Su et al. 2020), and provide protection against biotic and abiotic stresses including photo-oxidative damage (Dhar et al. 2020a; Gould 2004; Steyn et al. 2002). Flavonoid glycosides and caffeic acid derivatives trigger reactive oxygen species during abiotic and biotic stresses in addition to directly absorbing UV radiation (Gill and Tuteja 2010; Winkel-Shirley 2002). An increased flavonoid production trigged by the PAL activity and cinnamic acid biosynthesis occurs as a resistance response in tomato against $V$. dahliae race 1 isolate Le1087 (Hu et al. 2019), and these were previously documented as defense factors and signaling molecules (Shirley 1996; Treutter 2006). Furthermore, the red-pigmented lettuce is enriched in anthocyanin, which provides significant health benefit to humans through its high antioxidant activity (Rice-Evans and Paganga 1997; Qin et al. 2018). Robinson et al. (1983) listed six genetic loci controlling anthocyanin accumulation and its inheritance in lettuce. Zhang et al. (2017), using genome-wide association mapping, found 12 QTLs that regulate the expression of 
24 genes associated with flavonoid biosynthesis in lettuce. Thirtyfour structural genes associated with the anthocyanin pathway in red-type lettuce were identified using transcriptome analysis (Zhang et al. 2016). More recently, Su et al. (2020) mapped, cloned, and characterized four genes (RLL1, RLL2, rll3, and rll4) promoting anthocyanin accumulation in lettuce. Considering the high antioxidant content and defense-related functions of many flavonoids in plant biology, we aimed to map these traits in the genetic background of Sentry to obtain high-quality lettuce varieties with increased resistance to $V$. dahliae.

Overall, the Verticillium wilt management in many crops or cropping systems has primarily relied on an integrated approach of cultural, biological, and chemical methods and host resistance (Atallah et al. 2011; Hayes et al. 2011a, 2011b; Puri et al. 2021; Sandoya et al. 2017; Subbarao et al. 2017). However, factors such as the broader host range and long-lived microsclerotia of $V$. dahliae in soil (Atallah et al. 2011), ineffective cultural practices (Inderbitzin et al. 2018), prohibition of methyl bromide with the unavailability of equally effective fumigant alternatives (Duniway 2002; Meadows 2013), and unavailability of resistant cultivars (Hayes et al. 2007, 2018; Sandoya et al. 2017, 2021) have stymied the successful management of this devastating disease.

The emergence of a new race has posed renewed challenges to lettuce breeding programs already saddled with efforts to identify and incorporate resistance against the preexisting races 1 and 2 . It is therefore important to not only confirm the presence of race 3 among the $V$. dahliae populations from lettuce but also identify potential sources of resistance against this race and study the genetics of resistance. No genetic studies have been conducted thus far to elucidate resistance mechanisms against race 3 in tomato, lettuce, or other hosts.

The tunable genotyping-by-sequencing (tGBS) technology overcomes the high rate of genotypic errors and missing data that occur at the conventional genotyping-by-sequencing (GBS) approach, and for that reason, tGBS is one of the highly reliable technologies employed in the sequencing of heterozygous loci (Ott et al. 2017). The technology employs restriction enzymes to create overhangs in the opposite direction of DNA strands. A single-strand barcode adapter is ligated at each end, enabling the generation of high-quality GBS data with more than $97 \%$ accuracy during SNP calling (Ott et al. 2017). The technology is now widely used in many plant species, including vegetable and field crops such as lettuce (Simko et al. 2018), rice (Labroo et al. 2021), and corn (Li et al. 2021). Although the occurrence and distribution of race 3 in coastal California host systems is currently unknown, its emergence and eventual arrival in this area poses the most significant threat to lettuce production. Identifying new sources of resistance and their integration into the commercial cultivars will enable the preemptive management of this disease caused by $V$. dahliae race 3 when it eventually arrives. The current study was therefore conducted with a broader objective of identifying QTLs for resistance to $V$. dahliae race 3 using a biparental mapping population developed from a cross between cultivars Sentry and La Brillante and phenotyped in greenhouse conditions. Additionally, this study focused on identifying the QTLs controlling plant development and leaf variegation and explored the correlation among these traits to disease resistance in lettuce.

\section{MATERIALS AND METHODS}

\section{Initial disease screening}

Four $V$. dahliae isolates, namely VdLs16, the type isolate for race 1 in lettuce; $\mathrm{VdLs} 17$, the type isolate for race 2 from lettuce; and newly classified race 3 isolates 303 from spinach and CB86.7.2 from potato, were tested on three lettuce differential cultivars, La Brillante, Salinas, and Sentry, and three plant introductions (PI 171674, PI 204707, and PI 226641) with partial resistance to VdLs17 (Hayes et al. 2011a). These tests indicated that the race 1-resistant cultivars, La Brillante and Sentry, had differential responses to isolates VdLs17, CB86.7.2, and 303. Cultivar Sentry, which is as susceptible as La Brillante to the race 2 isolate (VdLs17), showed consistent partial resistance to isolates CB86.7.2 and 303, whereas La Brillante was as susceptible to these two isolates as it was to VdLs17 (Fig. 1). We hypothesized that Sentry could be used as a differential cultivar to differentiate race 2 from race 3 and utilized to map the genetic factors governing partial resistance.

\section{Population development and plant material}

A biparental mapping population was developed from a cross between race 3 partially resistant cultivar Sentry and the susceptible cultivar La Brillante. The $F_{1}$ progeny was selfed to get $F_{2}$ families. About $450 \mathrm{~F}_{2}$ seeds were randomly selected and used for seed increase to $\mathrm{F}_{2: 3}$ using the single-seed descent method. Of the $450 \mathrm{~F}_{2: 3}$ generated, 200 randomly selected lines were phenotyped against $V$. dahliae isolate 303 using replicated trials in the greenhouse.

\section{Phenotyping of families and cultivars}

The $200 \mathrm{~F}_{2: 3}$ families and parents were evaluated for their response to $V$. dahliae isolate 303 and two phenotypic traits in three greenhouse experiments (E1, E2, and E3) composed of at least seven replications (plants) at the U.S. Agricultural Research Station in Salinas, California, in the spring season of 2020. Approximately 90 seeds ( 2 to 3 per cell) of each $\mathrm{F}_{2: 3}$ family and the parental cultivars were sown in 128-well plug trays filled with sterilized Sunshine Mix number 4 (Sun Gro Horticulture, $\mathrm{AB}$, Canada) and kept in the dark for $48 \mathrm{~h}$ to facilitate uniform seed germination. Seedlings were progressively thinned to retain a single robust seedling per cell. The isolate culturing, inoculum preparation, and so on, were done as previously described (Puri et al. 2017). Briefly, $100 \mu \mathrm{l}$ of the cryopreserved isolate 303 suspensions at $-80^{\circ} \mathrm{C}$ in $25 \%$ glycerol was transferred into fullstrength PDA amended with 200 ppm of streptomycin and grown for a week. The conidia from the fully grown plate were further transferred into new PDA plates by streaking with an inoculation loop. The plates were then wrapped with parafilm and incubated at room temperature $\left(\sim 24^{\circ} \mathrm{C}\right)$ for 7 to 10 days. Inoculum was prepared by washing the cultures with sterilized $\mathrm{dd}_{2} \mathrm{O}$, and the contents were filtered through a double-layered cheesecloth and used for seedling inoculation.

Fourteen days after seedling emergence, the first inoculation with a suspension of $1 \times 10^{7}$ conidia/ml of $V$. dahliae isolate 303 was performed by nearly saturating the soil $(\sim 3 \mathrm{ml}$ inocu$\mathrm{lum} /$ well) in each cell. Two additional inoculations to ensure successful infection were done at 7 and 14 days after the first inoculation. Thirty-day-old inoculated and uninoculated seedlings were then transplanted into 500-ml Styrofoam cups filled with a 2:1 vol/vol mixture of pasteurized potting mix and sand. One week after transplanting, the fourth and final inoculation was performed by pouring $10 \mathrm{ml}$ of conidial suspension of $1 \times 10^{7}$ coni$\mathrm{dia} / \mathrm{ml}$ per cup. The seedlings from each family were arranged in a randomized complete block design, replicated at least seven times with seven single plants per replication $(202 \times 7=1,414$ total cups per experiment and three experiments). The control plants for each parent were treated with sterile distilled water 
at the same time as the inoculations and placed on a separate bench. Plants were grown for approximately 10 weeks until $70 \%$ of plants showed the first flower and were evaluated for disease symptoms. For disease evaluation, plants were uprooted, washed, and the taproot cut longitudinally to assess disease severity based on the extent of vascular discoloration along with the aboveground symptoms using the previously developed disease rating scale of 0 (symptomless) to 5 (most severe symptoms) (Hayes et al. 2011b).

In addition, at the time of disease rating, the plant development (index of plant development, IPD) stages were classified as prebolting (at rosette stage), bolting, or flowering. The number of plants with red or green leaf color was also recorded.

\section{Genotyping of families and cultivars}

At the 2- to 3-leaf stage, foliar tissue was collected from 259 $\mathrm{F}_{2}$ plants, both parents (Sentry and La Brillante), as well as from the cultivar Salinas that was previously used for the construction of lettuce reference genome and from an $\mathrm{F}_{1}$ plant (Sentry $\times \mathrm{La}$ Brillante). The leaf tissue was immediately lyophilized and submitted for DNA extraction and genotyping (Data2Bio, Ames, IA, http://www.data2bio.com) using the tGBS approach (Ott et al. 2017). Genotyping was performed on a single sample from each $F_{2}$ plant, five samples from the $F_{1}$ plant, and eight samples each from cultivars Sentry, La Brillante, and Salinas. Identification of SNPs and their physical position was based on the lettuce genome sequence of cultivar Salinas, version 8 (Reyes-Chin-Wo et al. 2017).

\section{Bioinformatic analyses}

Genotyping was performed with a modified tGBS protocol using digestion restriction enzyme Bsp1286I (Ott et al 2017). Lowquality reads with a Phred quality score below 15 of a total of 40 (63\% error rate) (Ewing et al. 1998; Ewing and Green 1998) were removed before alignment. The read quality was further assessed in a two-step process, where the initial reads were scanned at each end, and nucleotides with quality values lower than the threshold were removed. Next, the remaining nucleotides were scanned using an overlapping window of $10 \mathrm{bp}$, and all sequences below the average quality value threshold were trimmed using software LUCY 4.3 (Chou and Holmes 2001; Li and Chou 2004). The trimmed reads were then aligned to the reference genome using the Genomic Short-read Nucleotide Alignment Program (Wu and Nacu 2010). All high confident reads were filtered and used for subsequent analyses if mapped uniquely (e.g., $\leq 2$ mismatches every $36 \mathrm{bp}$ and fewer than five bases for every $75 \mathrm{bp}$ as tails).

\section{Bin map construction and genetic mapping}

The original dataset of 132,508 tGBS SNPs was first filtered using the following criteria for each SNP: Genotype data were available for more than $50 \%$ of samples, more than $87 \%$ of cultivar Salinas samples were homozygous and identical to the reference genome, more than $87 \%$ of cultivar Sentry samples were homozygous and identical, more than $87 \%$ of cultivar La Brillante samples were homozygous and identical, alleles of homozygous samples from one parent were different from alleles of homozygous samples of the other parent, and more than $80 \%$ of $F_{1}$ samples were heterozygous. The filtered set of 34,838 SNPs was used to construct a genetic bin map employing the sliding window approach (Huang et al. 2009). First, the detected SNPs were ordered according to their physical position in the reference genome. Consecutive SNPs were examined in a sliding window of 15 SNPs and a step size of a single SNP. As the window glided along the chromosome, recombination breakpoints were determined by the junction of two different genotypes, thus grouping consecutive markers into bins (Huang et al. 2009). A total of 1,741 identified bins of the physical map were subsequently used as markers to construct a genetic linkage map using $\mathrm{MST}_{\mathrm{MAP}}$ software (Wu et al. 2008), Kosambi mapping function, and LOD score of 10 . Seven bins not assigned to any of the nine LGs were eliminated from further analyses, leaving 1,734 bin markers in the genetic linkage map. The locations of bin markers on the physical and
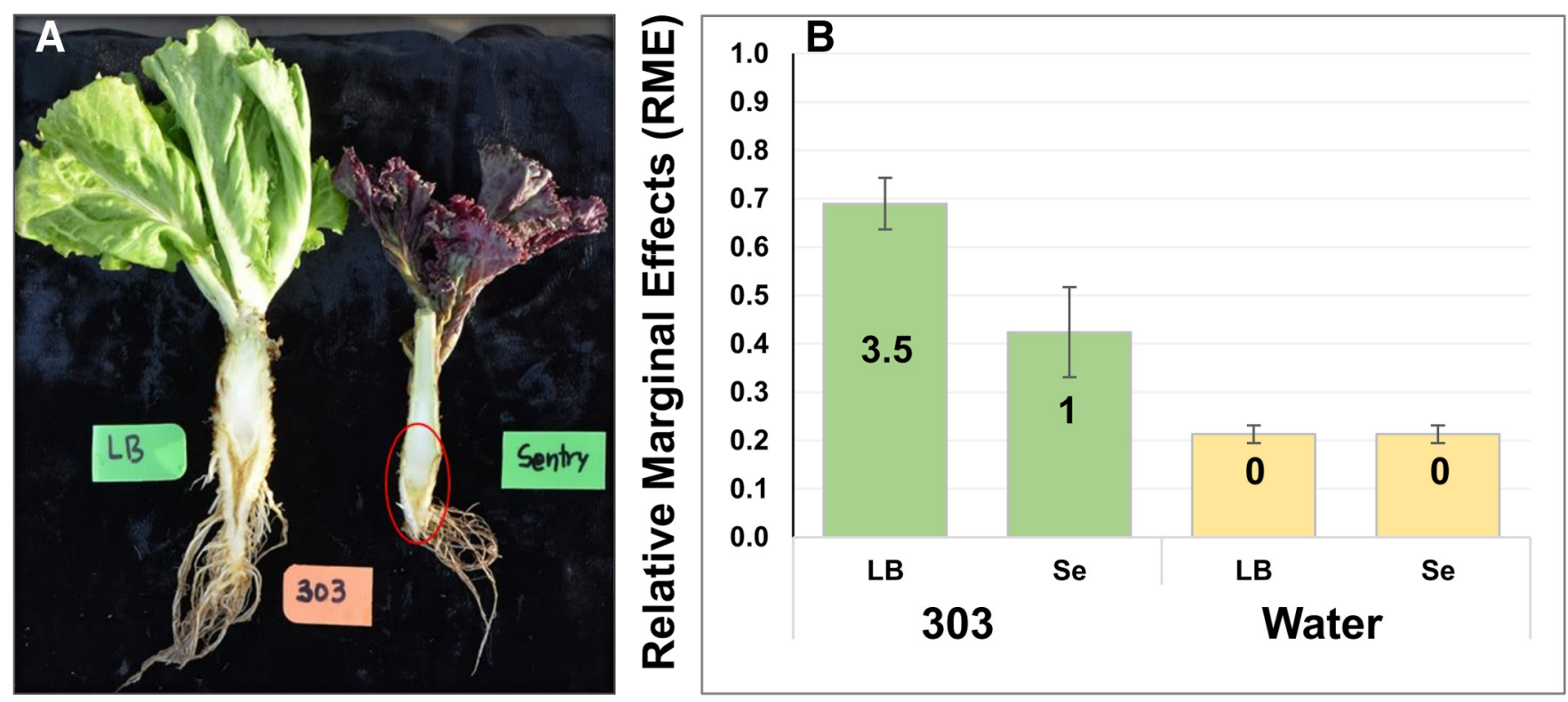

\section{FIGURE 1}

Symptoms of tap root discoloration on cultivars La Brillante (susceptible) and Sentry (partially resistant) inoculated with Verticillium dahliae race 3 isolate $303(\mathbf{A})$ and the relative marginal effects, median disease score (the numbers within the bars scored on a 0-to-5 scale), and confidence intervals (shown as error bars) associated with disease severity (B). 
genetic linkage maps were compared using Pearson $(r)$, Spearman $(\rho)$, and Kendall $(\tau)$ correlation coefficients implemented in JMP Pro 15.0.0 (SAS Institute, Cary, NC).

\section{QTL analysis}

QTL mapping was performed with QGene v. 4.4.0 software (Joehanes and Nelson 2008) using the composite interval mapping approach with an automated, forward selection of cofactors. The threshold for significant QTLs was set at the genome-wide $\alpha=0.05$ and determined through permutations with 1,000 iterations. The threshold for suggestive QTLs was set at $\alpha=0.1$. To minimize a type I error (false positive), suggestive QTLs were reported only if no significant QTL was detected for the particular experiment-trait combination.

The mode of inheritance was estimated from mean values detected at bins linked to the QTLs. The $d / a$ ratio was calculated from the values of dominance $(d)$ and additivity $(a)$, where $d=$ $\mu_{s l}-\left(\mu_{s s}+\mu_{l l}\right) / 2, a=\left(\mu_{s s}-\mu_{l l}\right) / 2$, and $\mu_{s s}, \mu_{l l}$, and $\mu_{s l}$ are the mean values for progeny homozygous for alleles originating from cultivar Sentry or cultivar La Brillante or heterozygous.

\section{Statistical analyses}

The phenotypic data of selected $200 \mathrm{~F}_{2: 3}$ families, parents, and controls from all three experiments (E1, E2, and E3) were analyzed. All phenotypic data were analyzed in JMP Genomics v. 8.1 (SAS Institute), if not mentioned otherwise. The traits analyzed included resistance to $V$. dahliae race 3 (VR3), plant development (IPD), and red leaf color (RLC). Individual experiments and the overall mean of the three experiments (EM) were statistically analyzed. The IPD was calculated from percentages of plants at bolting (BOL \%) and flowering (FLO \%) stages as follows: $\mathrm{IPD}=(\mathrm{BOL} \%+2 \times$ FLO $\%) / 200$. The index ranged from 0 , when all plants were at the rosette stage (pre-bolting), to 1 , when all plants were at the flowering stage. As the parental cultivars differ in leaf color (Sentry is red-colored, whereas La Brillante is green-colored), $\mathrm{F}_{2: 3}$ families were segregated for this trait. The presence of red leaf color on leaves was recorded and converted to 0 (green color) and 1 (red color) scale and used for downstream analysis.

The statistical analysis of phenotypic variation in disease severity was achieved by analysis of variance (ANOVA) fitting in the linear model $(l m)$ using the 'Stats' Package in R (R Core Team 2020). The relative marginal effects of disease severity in each parent for the initial screening were analyzed using the LD_CI macro at $95 \%$ confidence intervals (CIs) using SAS v. 9.4 (SAS Institute) (Shah and Madden 2004). The broad-sense heritability $\left(\mathrm{H}^{2}\right)$ of phenotypic data was calculated using the mixed model equations (mmer) function of the 'sommer' package in $\mathrm{R}$ using the formula $\mathrm{H}^{2}=\sigma^{2}{ }_{g} /\left(\sigma^{2}{ }_{g}+\sigma^{2}{ }_{e} / n\right)$, where $\sigma^{2}{ }_{g}$ is genetic variance, $\sigma_{e}^{2}$ is residual variance, and $n$ is the number of replications. The Pearson correlation coefficient $(r)$ was used to evaluate the linear relationship between traits or experiments. Basic mathematical calculations were performed in Microsoft Excel v. 16.52 (Microsoft, Redmond, WA), and statistical analyses were executed using JMP Pro v. 15.0.0 (SAS Institute).

\section{RESULTS}

\section{Phenotypic variation to Verticillium wilt}

In preliminary disease screening, both parents (i.e., Sentry and La Brillante) showed significantly different responses to $V$. dahliae isolate $303(P<0.05)$, with median disease severity ratings of 1 and 3.5, respectively (Fig. 1). All three greenhouse experiments and the overall mean showed a near normal distribution of $\mathrm{F}_{2: 3}$ families to their responses to $V$. dahliae race 3 , with means of 2.50 in E1 (range 0.67 to 4.71), 2.51 in E2 (range 0.25 to 4.33), 2.27 in E3 (range 0.14 to 4.14), and 2.42 in EM (range 0.97 to 4.10 ) (Fig. 2). The disease severity ratings for cultivar Sentry were lower than for La Brillante: 0.40 versus 1.88 in E1, 1.63 versus 3.67 in $\mathrm{E} 2,1.88$ versus 3.14 in $\mathrm{E} 3$, and 1.30 versus 2.89 in EM. These data indicate transgressive segregation of resistance in this population because the progeny had both a greater resistance than the partially resistant parent and greater susceptibility than the susceptible parent. The disease severity data from all three experiments were combined following the test of normality (Shapiro-Wilk test, $\mathrm{W}=0.997, p=0.42$ ). The ANOVA of disease severity on combined data indicated a significant variance among the $\mathrm{F}_{2: 3}$ families $(P<0.001)$. The broad-sense heritability

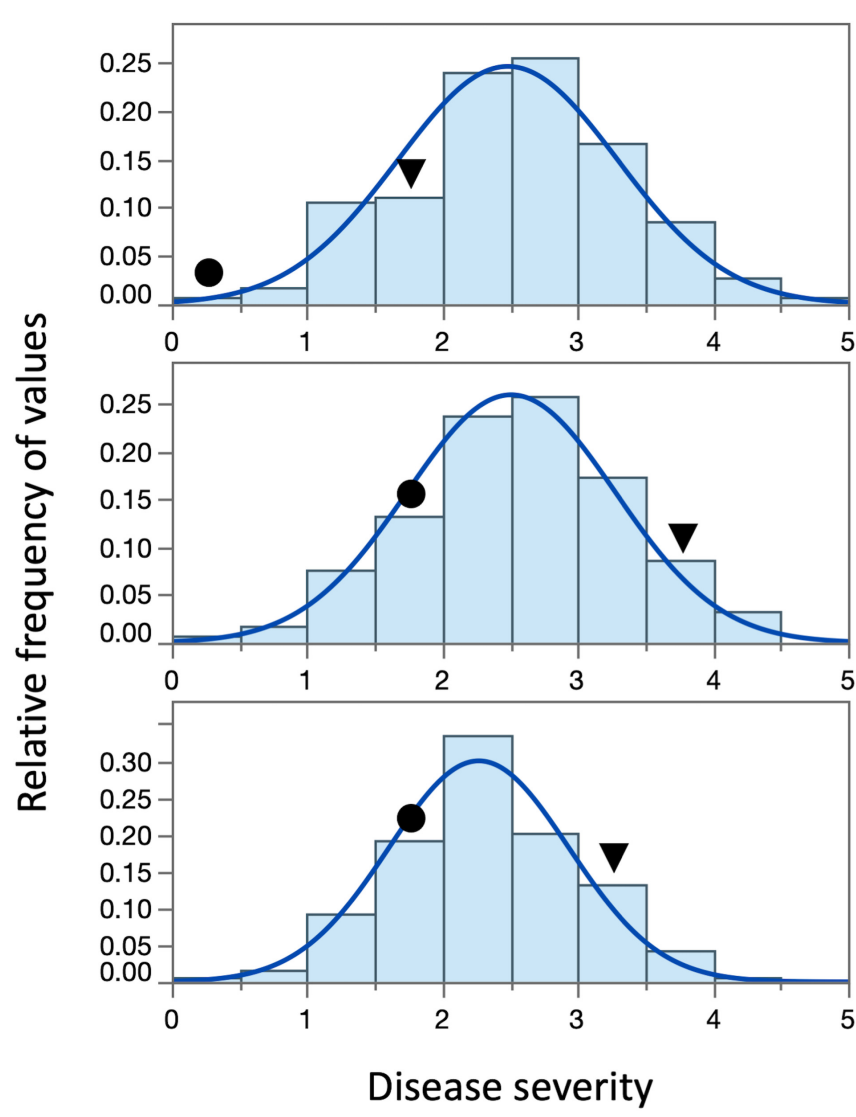

FIGURE 2

The frequency distribution of disease severity (DS) scores on $200 \mathrm{~F}_{2: 3}$ families to Verticillium dahliae race 3 isolate 303 in the greenhouse. The families were derived from a cross between race 3 partially resistant cultivar Sentry and the susceptible cultivar La Brillante. Disease scoring was done based on vascular root discoloration of tap root and foliar symptoms typical to Verticillium wilt on a 0-to- 5 scale, where $0=$ no vascular discoloration; $1=1$ to $25 \%$ of the vascular tissue exhibiting discoloration; $2=26$ to $50 \% ; 3=51$ to $75 \% ; 4=76$ to $100 \%$ discoloration and no foliar symptoms; and $5=100 \%$ discoloration and the presence of foliar symptoms (Hayes et al. $2011 \mathrm{~b})$. Average DS of 0 was classified as resistant, whereas scores up to 2 were classified as moderately resistant. The E1 (top), E2 (middle), and E3 (bottom) represent the three independent experiments with experimental means of $2.50,2.51$, and 2.27 , respectively. The EM is the overall mean (2.42) across three experiments. 
$\left(\mathrm{H}^{2}\right)$ was 0.618 with a standard error of 0.047 , demonstrating a strong genetic effect on the disease-resistance trait.

\section{Phenotypic variation in plant development and leaf color variation}

The $\mathrm{F}_{2: 3}$ progenies showed significant variation in plant development and red leaf color compared with the parents. The mean IPD score for Sentry and La Brillante was 0.40 and 0.19 , respectively, whereas the mean score for plants from $\mathrm{F}_{2: 3}$ families was 0.38 . The cultivar La Brillante had green leaf color, whereas Sentry had a red color. Approximately 63 families were only green colored, 52 were only red colored, and 85 comprised a mix of green- and red-colored plants.

\section{Correlation among various traits}

A significant but relatively weak correlation was observed among experiments in the reaction of families to $V$. dahliae E1 to $\mathrm{E} 2(r=0.346, P<0.0001)$, E1 to E3 $(r=0.400, P<0.0001)$, and E2 to E3 ( $r=0.332, P<0.0001)$ (Fig. 3). A stronger and highly significant correlation existed among experiments for both IPD $(r$ from 0.555 to $0.629, P<0.0001)$ and RLC ( $r$ from 0.463 to 0.545 , $P<0.0001)$. However, no significant correlation between disease severity and IPD ( $r$ from -0.073 to 0.048 , all $P>0.325$ ) or red leaf variegation ( $r$ from -0.121 to 0.135 , all $P>0.071$ ) was observed, indicating that Verticillium wilt resistance is not substantially associated with either plant development or the leaf color variation in lettuce as assessed at the time of resistance evaluation.

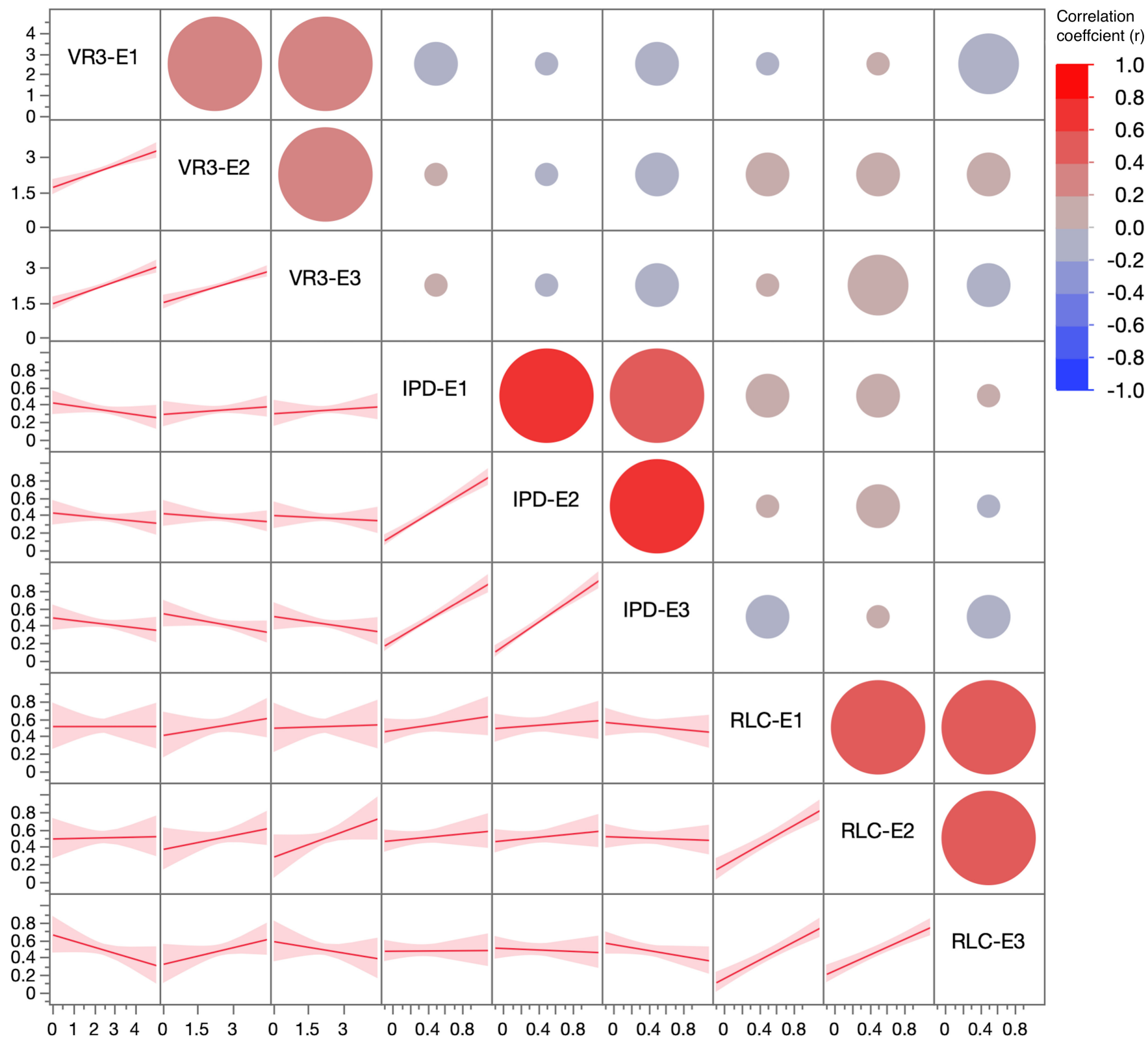

FIGURE 3

Correlations between Verticillium wilt disease severity (VR3), plant development (IPD), and red leaf color (RLC) evaluated in three experiments (E1, E2, and E3). Graphs below the diagonal line show the linear correlation trends between traits and the $95 \%$ confidence interval for the trend line. The color of circles in the graphs above the diagonal line indicates the value of Pearson correlation coefficients (scale is shown on the right side). Circle size indicates $P$ values, with a larger circle size meaning a more significant correlation. Only nine correlation coefficients between three experiments within each phenotypic trait were significant $(P<0.0001)$, all other correlation coefficients were not significant at $P=0.05$. 


\section{Development of genetic maps}

Following the quality control analysis of the initial set of 132,508 tGBS SNPs, a total of 34,838 filtered SNPs were used to construct the genetic linkage map and to map QTLs. The filtered SNPs were reduced to 1,734 bin markers that were positioned across nine chromosomal LGs (Fig. 4). The total genetic distance covered by the bin-based map was $1,883.5 \mathrm{cM}$, with the length of individual LGs ranging from $92.0 \mathrm{cM}$ (LG 6) to $304.2 \mathrm{cM}$ (LG 4). The highest number of bin markers were positioned on LG 8 (296 bins), whereas lowest number of bin markers were on LG 6 (79 bins).

The locations of bins on the genetic and physical (reference genome of 'Salinas V8') maps showed a very strong correlation for all LGs ( $r=0.963$ to $0.996, \rho=0.987$ to $0.999, \tau=0.925$ to 0.986 , all $P<0.0001$ ). From all LGs, the order of markers, as indicated by two nonparametric rank tests $(\rho, \tau)$, was relatively least congruent on LG 9 (Fig. 4). Detailed inspection of this $L G$ revealed a weak negative correlation in the order of about
20 markers located in the centromeric region $(\rho=-0.244, \tau=$ -0.207 , both nonsignificant with $P>0.14$ ) (Fig. 4).

\section{QTLs for resistance to V. dahliae race 3}

Composite interval mapping using a total of 1,734 SNP-based bin markers and phenotypic datasets detected three QTLs significantly associated with resistance to $V$. dahliae race 3 on two LGs (LG 2 and LG 4). The first QTL, qVR3-2.1, was detected in E2 (at a suggestive level) and EM experiments and explained 6.3 to $10.5 \%$ of the total phenotypic variation. The resistance allele originated from cultivar Sentry, and the dominance-to-additivity ratio $(d / a)$ test indicated additive to partially dominant resistance effect. The additional two significant QTLs for resistance were detected on LG 4, qVR3-4.1 in E1 and $q V R 3-4.2$ in E3, separated by approximately $50 \mathrm{cM}$. At both QTLs, the allele associated with resistance originated from the cultivar Sentry. Each of these QTLs explained almost $10 \%$ of the total phenotypic variation. There is a possibility, though, that these two loci represent a
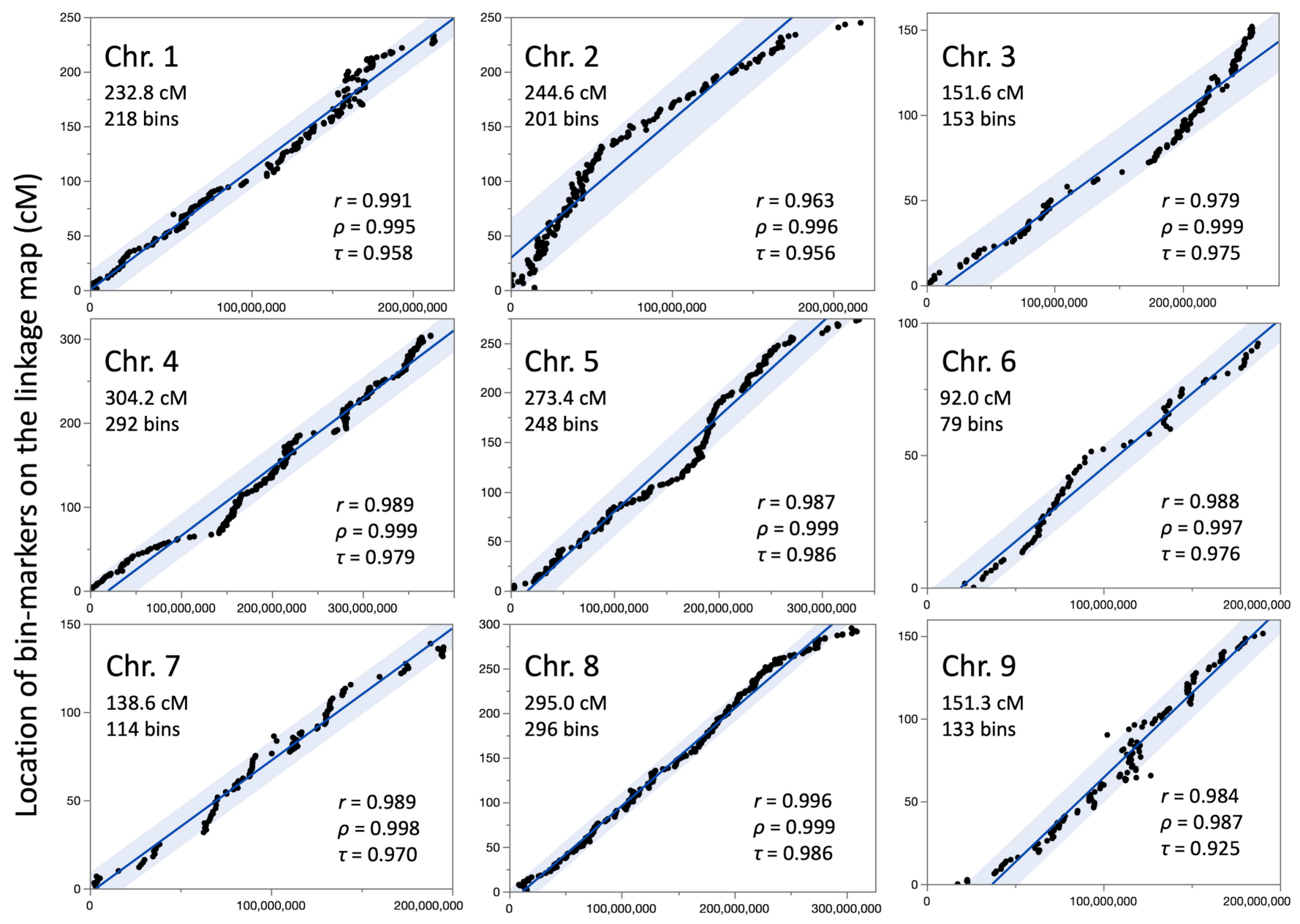

\section{Location of bin-markers on the physical map}

FIGURE 4

Relationship between the positions of bin markers on the physical map (horizontal axis) and the molecular linkage map (vertical axis). The bin position on the physical map is based on the location of the bin's first single nucleotide polymorphism (SNP) marker at the lettuce reference genome of cultivar Salinas, version 8 (Reyes-Chin-Wo et al. 2017). The best linear fit between two maps and its 95\% confidence interval is indicated by the blue lines and the light blue shaded areas, respectively. Values for Pearson $(r)$, Spearman $(\rho)$, and Kendall $(\tau)$ correlation coefficients are shown for each chromosome, as well as the number of bins in each linkage group and the linkage group length. All correlation coefficients were significant at $P<0.0001$. The whole linkage map is $1,883.5 \mathrm{cM}$ long, comprising 1,734 bins. 
single QTL but are detected in different chromosomal regions due to a relatively high variability in the phenotypic trait.

\section{QTLs for plant development}

Two QTLs significantly associated with plant development were detected on LG 2 and LG 7 (Table 1). The first QTL, qIPD2.1, was detected in E1, E3, and EM, and the second QTL, qIPD7.1, was detected in E1, E2, E3, and EM. The QTL qIPD-2.1 explained 11.8 to $25.3 \%$ of the phenotypic variation, whereas qIPD-7.1 explained 15.6 to $20.5 \%$ of the variation. Alleles for more rapid plant development, as indicated by the percentage of bolting and flowering plants, originated from both parents, cultivar La Brillante at $q I P D-2.1$ and cultivar Sentry at $q I P D-7.1$.

\section{QTLs for red leaf color variation}

Only a single QTL was identified that was associated with red leaf color in all experiments (Table 1). A QTL, $q R L C-9.1$, significantly associated with red leaf color was positioned on LG 9, which explained 29.0 to $45.8 \%$ of the total phenotypic variation of the trait, and alleles for red color originated from red-colored cultivar Sentry.

\section{DISCUSSION}

Resistance in lettuce to different races of $V$. dahliae is either governed by a single dominant gene $(V r l)$ as in race 1 (Hayes et al. 2011a) or is a function of complex genetic traits governed by a few highly environment-dependent QTLs (e.g., qVERT6.1) as in race 2 (Sandoya et al. 2021). Besides lettuce, in many other hosts, including tomato, cotton, and sunflower, resistance to race 1 is governed by a single dominant locus (Fick and Zimmer 1974; Hayes et al. 2011a; Mert et al. 2005; Schaible et al. 1951). The resistance against race 2 is host dependent and governed by a single gene in tomato (Stamova 2005; Usami et al. 2017), whereas 12 QTLs governing resistance against race 2 have been reported in lettuce (Sandoya et al. 2021). The complex genetic makeup of $V$. dahliae races from lettuce and tomato (ChavarroCarrero et al. 2021; Wang et al. 2021), and the unavailability of differential host cultivars to identify races among $V$. dahliae populations poses greater complexity for lettuce-breeding programs. The $V$. dahliae isolate 303 used in this experiment carries avirulence gene characteristic for race 3 (VdAve3) and is structurally different from many originally classified race 2 isolates, including VdLs17 (Wang et al. 2021). This study, thus, will provide a foundation for genetic studies to elucidate resistance mechanisms against $V$. dahliae race 3 in lettuce.

Using 259 (Sentry $\times$ La Brillante) $\mathrm{F}_{2}$ progeny, 132,508 tGBS SNPs, and a sliding window approach, we constructed an ultrahigh-density genetic linkage map comprising 1,734 bins with a total length of $1,883.5 \mathrm{cM}$. This map is similar in length to the ultra-high-density linkage map $(1,585 \mathrm{cM})$ constructed using the interspecific mapping population (L. sativa cultivar Salinas $\times$ L. serriola accession US96UC23) of $213 \mathrm{~F}_{7}$ recombinant inbred lines (RILs) (Truco et al. 2013).

Phenotyping of 200 randomly selected $\mathrm{F}_{2: 3}$ families revealed three QTLs for resistance to $V$. dahliae race 3. Each of these QTLs explained up to $\sim 10 \%$ of the total phenotypic variation for the trait. The resistance alleles for all three QTLs originated from cultivar Sentry that is partially resistant to $V$. dahliae race 3. The $q V R 3-4.2$ is positioned in the same chromosomal region as $q V E R T 4.2$ for resistance to $V$. dahliae race 2 (Sandoya et al. 2021). Notably, this QTL is located in the major resistance cluster (MRC4) that contains several candidate genes involved in disease resistance (Christopoulou et al. 2015). The qVR3-2.1 seemed to be separated from MRC2 located on chromosome 2 (Christopoulou et al. 2015). However, sequence annotation of this chromosomal region revealed at least two candidate resistance genes (PADRE protein upregulated after infection by Sclerotinia sclerotiorum, AT3G03280.1, and NB-ARC domain-containing disease-resistance protein AT3G14470.1) (Didelon et al. 2020; Nandety et al. 2013) within $200 \mathrm{~kb}$ of $q V R 3-2.1$.

The resistance alleles from $q V R 3-2.1$ and $q V R 3-4.2$ showed an additive effect. When La Brillante alleles in a homozygous state were present at both loci, the average disease score (in EM)

TABLE 1

Quantitative trait loci (QTLs) identified for resistance to $V$. dahliae race 3 (VR3), plant development, and red leaf color in the Sentry $\times$ La Brillante mapping population

\begin{tabular}{|c|c|c|c|c|c|c|c|c|c|}
\hline Trait & QTL & LG & Position $(\mathrm{cM})^{\mathrm{a}}$ & Position (physical) ${ }^{b}$ & Peak LOD & $\mathrm{R}^{2}(\%)$ & $d / a^{\mathrm{c}}$ & Origin $^{\mathrm{d}}$ & Experiment $^{\mathrm{e}}$ \\
\hline \multirow[t]{4}{*}{ VR3 } & $q V R 3-2.1$ & 2 & 213.7 & $154,445,004$ & 4.6 & 10.5 & 0.59 & Sen & EM \\
\hline & qVR3-2.1 & 2 & 215.6 & $156,118,795$ & $2.7^{\mathrm{f}}$ & 6.3 & 0.67 & Sen & $\mathrm{E} 2$ \\
\hline & $q V R 3-4.1$ & 4 & 198.7 & $281,126,519$ & 4.3 & 9.8 & 0.56 & Sen & E1 \\
\hline & $q V R 3-4.2$ & 4 & 249.5 & $322,393,238$ & 4.4 & 9.9 & -0.38 & Sen & E3 \\
\hline \multirow[t]{7}{*}{ IPD } & $q I P D-2.1$ & 2 & 2.1 & $14,743,078$ & 11.8 & 25.3 & -0.28 & LB & E1 \\
\hline & $q I P D-2.1$ & 2 & 3.1 & $1,134,532$ & 9.6 & 20.1 & -0.56 & LB & EM \\
\hline & $q I P D-2.1$ & 2 & 4.2 & $1,134,532$ & 5.2 & 11.8 & -0.91 & LB & E3 \\
\hline & $q I P D-7.1$ & 7 & 1.1 & $3,239,861$ & 9.8 & 20.5 & -0.37 & Sen & EM \\
\hline & $q I P D-7.1$ & 7 & 1.9 & $3,239,861$ & 8.1 & 17.7 & -0.35 & Sen & E3 \\
\hline & $q I P D-7.1$ & 7 & 2.1 & $2,775,830$ & 6.6 & 15.6 & -0.56 & Sen & E2 \\
\hline & $q I P D-7.1$ & 7 & 6.8 & $3,700,693$ & 6.9 & 15.7 & -0.08 & Sen & E1 \\
\hline \multirow[t]{4}{*}{ RLC } & $q R L C-9.1$ & 9 & 108.8 & $149,474,495$ & 17.4 & 33.5 & 0.05 & Sen & E3 \\
\hline & $q R L C-9.1$ & 9 & 108.8 & $149,474,495$ & 26.2 & 45.8 & 0.24 & Sen & EM \\
\hline & $q R L C-9.1$ & 9 & 114.4 & $149,944,505$ & 13.1 & 29.0 & 0.36 & Sen & E2 \\
\hline & $q R L C-9.1$ & 9 & 117.1 & $147,291,926$ & 12.9 & 36.8 & 0.52 & Sen & E1 \\
\hline
\end{tabular}

${ }^{a}$ Position of nearest bin on the molecular linkage map.

${ }^{b}$ Position of the nearest bin on the physical map. The bin position was based the position of the bin's first single nucleotide polymorphism marker on the lettuce genome sequence of cultivar Salinas, version 8 (Reyes-Chin-Wo et al. 2017).

c $d / a$ is the dominance-to-additivity ratio that indicates the mode of inheritance. The value of 1 indicates that alleles from cultivar Sentry are dominant, the value of 0 indicates that alleles have an additive effect, and the value of -1 indicates that alleles cultivar La Brillante are dominant.

${ }^{\mathrm{d}}$ Origin of the alleles associated with higher disease resistance (VR3), more advanced developmental stage, or red leaf color. LB $=$ alleles originating from cultivar La Brillante; Sen = alleles originating from cultivar Sentry.

e Three experiments (E1, E2, E3) and the mean of the three experiments (EM).

f Suggestive QTL at genome-wide $\alpha \leq 0.1$. 
was 3.06, whereas when alleles originating from cultivar Sentry were homozygous at the two loci, the average disease score was only 1.82. For comparison, the average disease score (in EM) of cultivar La Brillante was 2.89, whereas that for cultivar Sentry was 1.30. Together with observed transgressive segregation in $\mathrm{F}_{2: 3}$ families, these data indicate that more alleles for resistance to $V$. dahliae race 3 were present in this population, some of which might originate from the susceptible cultivar La Brillante. Although cultivar La Brillante is more susceptible to race 3 than cultivar Sentry is, it harbors $V r l$, the single dominant gene of major effect for resistance to $V$. dahliae race 1 located at LG 9 (Hayes et al. 2011b; Inderbitzin et al. 2019). However, additional loci might exist in this cultivar that provide a minor effect for resistance to other races of $V$. dahliae besides race 1 .

Understanding of Verticillium wilt severity-related traits such as plant height, development, bolting, and flowering are important for detecting the disease-resistance dependency and complexity of those traits. Unlike a strong positive correlation of $A$. thaliana late-flowering type to $F$. oxysporum wilt resistance (Lyons et al. 2015b), no relationship was observed between the plant development, flowering, and disease-resistance phenotype in the present study. Sandoya et al. (2021) also reported a different plant-pathogen interaction from the one observed here in $V$. dahliae race 2-lettuce interaction, where infected plants became more symptomatic at the flowering stage. However, this agrees with the previous finding of negative correlations between bolting and lettuce drop within and between environments (Hayes et al. 2010; Mamo et al. 2019). Thus, such a relationship observed in the current study was likely either because of the absence of an association between the genomic loci conferring plant development and disease resistance or because of microclimatic variations or a combination of both.

Although cultivars Sentry and La Brillante had an approximately similar rate of development, two significant alleles were detected to be associated with IPD, $q I P D-2.1$ and $q I P D-7.1$. Considering a substantial transgressive segregation for IPD in this population, it is not surprising that alleles for more rapid development originated both from cultivar La Brillante ( $q I P D-2.1$ ) and cultivar Sentry ( $q I P D-7.1)$. More than 160 QTLs were previously reported to be associated with plant development (Han et al. 2021; Simko et al. 2021), including those for bolting and flowering located in the same region of LG7 ( $q F L T 7.5, s q B L T 7.1)$ and LG $2(q B F r 2.1)$ as the QTLs detected in this study (Rosental et al. 2021; Sandoya et al. 2021). These two genomic regions harbor major clusters of genes reported to be linked with lettuce bolting and flowering (Han et al. 2021). QTL qIPD-2.1 is colocated with $q B F r 2.1$, the major locus for bolting/flowering identified in another mapping population and tightly linked with a lettuce homolog of the Flowering Locus $T$ (LsFT) from Arabidopsis (Rosental et al. 2021).

Leaves of cultivar Sentry are red colored, whereas leaves of cultivar La Brillante have a light green color. The red color of lettuce leaves is caused by anthocyanins (Simko 2020). At least six candidate genes responsible for the variation of anthocyanin in lettuce leaves were previously described (Zhang et al. 2017). The major QTL detected in this study $(q R L C-9.1)$ on LG 9 is colocated with $R 9$ for anthocyanin production originating from cultivar 'Eruption' (Mamo et al. 2019). Considering the similarity in the chromosomal locations, this QTL might be associated with the candidate gene for leaf color, ANS (anthocyanidin synthase) (Zhang et al. 2017). The high phenotypic variation governed by QTL ( $q R L C-9.1)$ indicated that red leaf color in this population is likely controlled by a major gene.

In conclusion, cultivar Sentry contains loci for resistance to V. dahliae race 3 and thus can be used to develop lettuce-breeding lines with partial resistance against this pathogen. Sandoya et al. (2021) identified a major QTL at LG 6 (qVERT6.1) against the race 2 isolate VdLs17 in the genetic background of $L$. sativa and L. serriola. Thus, the QTLs identified in the Sentry background will diversify the resistance gene pool for the overall race 2 and race 3 breeding programs and open up the possibility of gene pyramiding. Markers linked to the resistance QTLs described in this study can aid in the introgression of the resistance loci and alleles into desirable genotypes using marker-assisted selection. Additional genetic and functional studies are needed, however, to identify the genes that confer phenotypes with partial resistance to $V$. dahliae race 3 .

\section{ACKNOWLEDGMENTS}

The authors thank Rosa Marchebout, Lorraine Landeros, Denise Soto, and Bullo Erena Mamo for assistance in different phases of this research. Special thanks to Jose Orozco for developing the $F_{1}$ cross.

\section{LITERATURE CITED}

Atallah, Z. K., Hayes, R. J., and Subbarao, K. V. 2011. Fifteen years of Verticillium wilt of lettuce in America's salad bowl: A tale of immigration, subjugation, and abatement. Plant Dis. 95:784-792.

Chavarro-Carrero, E. A., Vermeulen, J. P., Torres, D. E., Usami, T., Schouten, H. J., Bai, Y., Seidl, M. F., and Thomma, B. P. H. J. 2021. Comparative genomics reveals the in planta-secreted Verticillium dahliae Av2 effector protein recognized in tomato plants that carry the $V 2$ resistance locus. Environ. Microbiol. 23:1941-1958.

Chen, T., Kan, J., Yang, Y., Ling, X., Chang, Y., and Zhang, B. 2016. A $V e$ homologous gene from Gossypium barbadense, Gbvdr3, enhances the defense response against Verticillium dahliae. Plant Physiol. Biochem. 98:101-111.

Chou, H. H., and Holmes, M. H. 2001. DNA sequence quality trimming and vector removal. Bioinformatics 17:1093-1104.

Christopoulou, M., Wo, S. R. C., Kozik, A., Mchale, L. K., Truco, M. J., Wroblewski, T., and Michelmore, R. W. 2015. Genome-wide architecture of disease resistance genes in lettuce. G3 (Bethesda) 5:2655-2669.

Dhar, N., Caruana, J. S., Erdem, I., Subbarao, K. V., Klosterman, S. J., and Raina, R. 2020b. The Arabidopsis Senescence Associated Gene 13 regulates senescence and plays contrasting roles in the defense against bacterial and fungal pathogens. Mol. Plant Microbe Interact. 33:754-766.

Dhar, N., Chen, J. Y., Subbarao, K. V., and Klosterman, S. J. 2020a. Hormone signaling and its interplay with development and defense responses in Verticillium-plant interactions. Front. Plant Sci. 11:584997.

Dhar, N., Short, D. P. G., Mamo, B. E., Corrion, A. J., Wai, C. M., Anchieta, A., Vanburen, R., Day, B., Ajwa, H., Subbarao, K. V., and Klosterman, S. J. 2019. Arabidopsis defense mutant $n d r l-1$ displays accelerated development and early flowering mediated by the hormone gibberellic acid. Plant Sci. 285:200-213.

Didelon, M., Khafif, M., Godiard, L., Barbacci, A., and Raffaele, S. 2020. Patterns of sequence and expression diversification associate members of the $P A D R E$ gene family with response to fungal pathogens. Front. Genet. 11:491.

Duniway, J. M. 2002. Status of chemical alternatives to methyl bromide for pre-plant fumigation of soil. Phytopathology 92:1337-1343.

Ewing, B. and Green, P. 1998. Base-calling of automated sequencer traces using Phred. II. Error probabilities. Genome Res. 8:186-194.

Ewing, B., Hillier, L., Wendl, M. C., and Green, P. 1998. Base-calling of automated sequencer traces using Phred. I. Accuracy assessment. Genome Res. 8:175-185.

Fick, G. N., and Zimmer, D. E. 1974. Monogenic resistance to Verticillium wilt in sunflowers. Crop Sci. 14:895-896.

Fradin, E. F., Zhang, Z., Juarez Ayala, J. C., Castroverde, C. D. M., Nazar, R. N., Robb, J., Liu, C.-M., and Thomma, B. P. H. J. 2009. Genetic dissection of Verticillium wilt resistance mediated by tomato Ve1. Plant Phys. 150:320-332.

Gill, S. S., and Tuteja, N. 2010. Reactive oxygen species and antioxidant machinery in abiotic stress tolerance in crop plants. Plant Physiol. Biochem. 48:909-930.

Gould, K. S. 2004. Nature's Swiss army knife: The diverse protective roles of anthocyanins in leaves. J. Biomed. Biotechnol. 2004:314-320.

Häffner, E., Karlovsky, P., and Diederichsen, E. 2010. Genetic and environmental control of the Verticillium syndrome in Arabidopsis thaliana. BMC Plant Biol. 10:235. 
Han, R., Truco, M. J., Lavelle, D. O., and Michelmore, R. W. 2021. A composite analysis of flowering time regulation in lettuce. Front. Plant Sci. 12:632708.

Hayes, R. J., Maruthachalam, K., Vallad, G. E., Klosterman, S. J., and Subbarao, K. V. 2011a. Selection for resistance to Verticillium wilt caused by race 2 isolates of Verticillium dahliae in accessions of lettuce (Lactuca sativa L.). HortScience 46:201-206.

Hayes, R. J., McHale, L. K., Vallad, G. E., Truco, M. J., Michelmore, R. W., Klosterman, S. J., Maruthachalam, K., and Subbarao, K. V. 2011b. The inheritance of resistance to Verticillium wilt caused by race 1 isolates of Verticillium dahliae in the lettuce cultivar La Brillante. Theor. Appl. Gen. 123:509-517.

Hayes, R. J., Sandoya, G., Mou, B., Simko, I., and Subbarao, K. V. 2018. Release of three iceberg lettuce populations with combined resistance to two soilborne diseases. HortScience 53:247-250.

Hayes, R. J., Vallad, G. E., Qin, Q. M., Grube, R. C., and Subbarao, K. V. 2007. Variation for resistance to Verticillium wilt in lettuce (Lactuca sativa L.). Plant Dis. 91:439-445.

Hayes, R. J., Wu, B. M., Pryor, B. M., Chitrampalam, P., and Subbarao, K. V. 2010. Assessment of resistance in lettuce (Lactuca sativa L.) to mycelial and ascospore infection by Sclerotinia minor Jagger and S. sclerotiorum (Lib.) de Bary. HortScience 45:333-341.

Hu, X., Puri, K. D., Gurung, S., Klosterman, S. J., Wallis, C. M., Britton, M., Durbin-Johnson, B., Phinney, B., Salemi, M., Short, D., and Subbarao, K. V. 2019. Proteome and metabolome analyses reveal differential responses in tomato-Verticillium dahliae-interactions. J. Proteomics 207:103449.

Huang, X., Feng, Q., Qian, Q., Zhao, Q., Wang, L., Wang, A., Guan, J., Fan, D., Weng, Q., Huang, T., Dong, G., Sang, T., and Han, B. 2009. High-throughput genotyping by whole-genome resequencing. Genome Res. 19:1068-1076.

Huot, B., Yao, J., Montgomery, B. L., and He, S. Y. 2014. Growth-defense tradeoffs in plants: A balancing act to optimize fitness. Mol. Plant 7: 1267-1287.

Inderbitzin, P., Christopoulou, M., Lavelle, D., Reyes-Chin-Wo, S., Michelmore, R. W., Subbarao, K. V., and Simko, I. 2019. The LsVe1L allele provides a molecular marker for resistance to Verticillium dahliae race 1 in lettuce. BMC Plant Biol. 19:305.

Inderbitzin, P., and Subbarao, K. V. 2014. Verticillium systematics and evolution: How confusion impedes Verticillium wilt management and how to resolve it. Phytopathology 104:564-574.

Inderbitzin, P., Ward, J., Barbella, A., Solares, N., Izyumin, D., Burman, P., Chellemi, D. O., and Subbarao, K. V. 2018. Soil microbiomes associated with Verticillium wilt-suppressive broccoli and chitin amendments are enriched with potential biocontrol agents. Phytopathology 108:31-43.

Ingram, T. W., Oh, Y., Adhikari, T. B., Louws, F. J., and Dean, R. A. 2020. Comparative genome analyses of 18 Verticillium dahliae tomato isolates reveals phylogenetic and race specific signatures. Front. Microbiol. 11:573755.

Joehanes, R., and Nelson, J. C. 2008. QGene 4.0, an extensible Java QTLanalysis platform. Bioinformatics 24:2788-2789.

Kano, K., and Usami, T. 2019. Race 3 tomato Verticillium wilt pathogen potentially derives from race 1 isolate. Soil Microorg. 73:71-78.

Klosterman, S. J., Atallah, Z. K., Vallad, G. E., and Subbarao, K. V. 2009. Diversity, pathogenicity, and management of Verticillium species. Annu. Rev. Phytopathol. 47:39-62.

Labroo, M. R., Ali, J., Aslam, M. U., de Asis, E. J., Paz Dela, M. A., Sevilla, M. A., Lipka, A. E., Studer, A. J., and Rutkoski, J. E. 2021. Genomic prediction of yield traits in single-cross hybrid rice (Oryza sativa L.). Front. Genet. 12:692870.

Li, J., Li, D., Espinosa, C. Z., Pastor, V. T., Rasheed, A., Rojas, N. P., Wang, J., Varela, A. S., Carolina de Almeida Silva, N., Schnable, P. S., Costich, D. E., and Li, H. 2021. Genome-wide analyses reveal footprints of divergent selection and popping-related traits in CIMMYT's maize inbred lines. J. Exp. Bot. 72:1307-1320.

Li, S., and Chou, H. H. 2004. LUCY2: An interactive DNA sequence quality trimming and vector removal tool. Bioinformatics 20:2865-2866.

Ligoxigakis, E. K., Vakalounakis, D. J., and Thanassoulopoulos, C. C. 2002. Weed hosts of Verticillium dahliae in Crete: Susceptibility, symptomatology and significance. Phytoparasitica 30:511-518.

Lyons, R., Rusu, A., Stiller, J., Powell, J., Manners, J. M., and Kazan, K. 2015a. Investigating the association between flowering time and defense in the Arabidopsis thaliana-Fusarium oxysporum interaction. PLoS One 10:e0127699.

Lyons, R., Stiller, J., Powell, J., Rusu, A., Manners, J. M., and Kazan, K. 2015b. Fusarium oxysporum triggers tissue-specific transcriptional reprogramming in Arabidopsis thaliana. PLoS One 10:e121902.

Mamo, B. E., Hayes, R. J., Truco, M. J., Puri, K. D., Michelmore, R. W., Subbarao, K. V., and Simko, I. 2019. The genetics of resistance to lettuce drop (Sclerotinia spp.) in lettuce in a recombinant inbred line population from Reine des Glaces $\times$ Eruption. Theor. Appl. Gen. 132:2439-2460.

Maruthachalam, K., Atallah, Z. K., Vallad, G. E., Klosterman, S. J., Hayes, R. J., Davis, R. M., and Subbarao, K. V. 2010. Molecular variation among isolates of Verticillium dahliae and polymerase chain reaction-based differentiation of races. Phytopathology 100:1222-1230.

Meadows, R. 2013. News overview: Researchers develop alternatives to methyl bromide fumigation. Calif. Agric. 67:125-127.

Mert, M., Kurt, S., Gencer, O., Akiscan, Y., Boyaci, K., and Tok, F. M 2005. Inheritance of resistance to Verticillium wilt (Verticillium dahliae) in cotton (Gossypium hirsutum L.). Plant Breed. 124:102-104.

Nandety, R. S., Caplan, J. L., Cavanaugh, K., Perroud, B., Wroblewski, T., Michelmore, R. W., and Meyers, B. C. 2013. The role of TIR-NBS and TIR-X proteins in plant basal defense responses. Plant Physiol. 162: 1459-1472.

Nazar, R. N., Xu, X., Kurosky, A., and Robb, J. 2018. Antagonistic function of the Ve R-genes in tomato. Plant Mol. Biol. 98:67-79.

Ogawara, T., Higashi, K., Kamada, H., and Ezura, H. 2003. Ethylene advances the transition from vegetative growth to flowering in Arabidopsis thaliana. J. Plant Physiol. 160:1335-1340.

Ott, A., Liu, S., Schnable, J. C., Yeh, C. T. E., Wang, K. S., and Schnable, P. S. 2017. GBS $^{\circledR}$ genotyping-by-sequencing enables reliable genotyping of heterozygous loci. Nucleic Acids Res. 45:e178.

Pegg, G. F., and Brady, B. L. 2002. Verticillium Wilts. CABI Publishing, Wallingford, U.K.

Puri, K. D., Gurung, S., Short, D. P. G., Atallah, Z. K., Sandoya, G., Davis, R. M., Hayes, R. J., and Subbarao, K. V. 2017. Short-term host selection pressure has little effect on the evolution of a monoclonal population of Verticillium dahliae Race 1. Phytopathology 107:1417-1425.

Puri, K. D., Hu, X., Gurung, S., Short, D., Sandoya Miranda, G. V., Schild, M., Zhang, Y., Zhao, J., Anchieta, A., Klosterman, S. J., and Subbarao, K. 2021. Verticillium klebahnii and V. isaacii isolates exhibit host-dependent biological control of Verticillium wilt caused by $V$. dahliae. PhytoFrontiers 1:276-290.

Puri, K. D., Vallad, G. E., Qin, Q. M., Hayes, R. J., and Subbarao, K. V. 2019. Harvest of lettuce from Verticillium-infested fields has little impact on postharvest quality. Plant Dis. 103:668-676

Qin, X. X., Zhang, M. Y., Han, Y. Y., Hao, J. H., Liu, C. J., and Fan, S. X. 2018. Beneficial phytochemicals with anti-tumor potential revealed through metabolic profiling of new red pigmented lettuces (Lactuca sativa L.). Int. J. Mol. Sci. 19:1165

R Core Team 2020. R: A language and environment for statistical computing. R Foundation for Statistical Computing, Vienna, Austria.

Reyes-Chin-Wo, S., Wang, Z., Yang, X., Kozik, A., Arikit, S., Song, C., Xia, L., Froenicke, L., Lavelle, D. O., Truco, M.-J., Xia, R., Zhu, S., Xu, C., Xu, H., Xu, X., Cox, K., Korf, I., Meyers, B. C., and Michelmore, R. W. 2017. Genome assembly with in vitro proximity ligation data and whole-genome triplication in lettuce. Nat. Commun. 8:14953.

Rice-Evans, C., Miller, N., and Paganga, G. 1997. Antioxidant properties of phenolic compounds. Trends Plant Sci. 2:152-159.

Robinson, R. W., McCreight, J. D., and Ryder, E. J. 1983. The genes of lettuce and closely related species. Plant Breed. Rev. 1:267-293.

Rosental, L., Still, D. W., You, Y., Hayes, R. J., and Simko, I. 2021. Mapping and identification of genetic loci affecting earliness of bolting and flowering in lettuce. Theor. Appl. Gen. 134:3319-3337.

Sandoya, G. V., Gurung, S., Short, D. P., Subbarao, K. V., Michelmore, R. W., and Hayes, R. J. 2017. Genetics of resistance in lettuce to races 1 and 2 of Verticillium dahliae from different host species. Euphytica 213:1-12.

Sandoya, G. V., Truco, M. J., Bertier, L. D., Subbarao, K. V., Simko, I., Hayes, R. J., and Michelmore, R. W. 2021. Genetics of partial resistance against Verticillium dahliae race 2 in wild and cultivated lettuce. Phytopathology 111:842-849.

Schaible, L., Cannon, O., and Waddoups, V. 1951. Inheritance of resistance to Verticillium wilt in a tomato cross. Phytopathology 41:986-990.

Shah, D. A., and Madden, L. V. 2004. Nonparametric analysis of ordinal data in designed factorial experiments. Phytopathology 94:33-43.

Shirley, B. W. 1996. Flavonoid biosynthesis: 'New' functions for an 'old' pathway. Trends Plant Sci. 1:377-382.

Short, D. P., Gurung, S., Maruthachalam, K., Atallah, Z. K., and Subbarao, K. V. 2014. Verticillium dahliae race 2-specific PCR reveals a high frequency of race 2 strains in commercial spinach seed lots and delineates race structure. Phytopathology 104:779-785.

Simko, I. 2020. Predictive modeling of a leaf Conceptual Midpoint QuasiColor (CMQ) using an artificial neural network. Sensors 20:3938.

Simko, I., Costanzo, S., Haynes, K. G., Christ, B. J., and Jones, R. W. 2004 Linkage disequilibrium mapping of a Verticillium dahliae resistance quantitative trait locus in tetraploid potato (Solanum tuberosum) through a candidate gene approach. Theor. Appl. Gen. 108:217-224. 
Simko, I., Hayes, R. J., Truco, M. J., Michelmore, R. W., Antonise, R., and Massoudi, M. 2018. Molecular markers reliably predict post-harvest deterioration of fresh-cut lettuce in modified atmosphere packaging. Hort. Res. 5:21.

Simko, I., Jia, M., Venkatesh, J., Kang, B.-C., Weng, Y., Barcaccia, G., Lanteri, S., Bhattarai, G., and Foolad, M. R. 2021. Genomics and markerassisted improvement of vegetable crops. Crit. Rev. Plant. Sci. 40:303-365.

Singh, V., Roy, S., Singh, D., and Nandi, A. K. 2014. Arabidopsis FLOWERING LOCUS D influences systemic-acquired-resistance-induced expression and histone modifications of WRKY genes. J. Biosci. 39: 119-126.

Song, Y., Zhang, Z., Seidl, M. F., Majer, A., Jakse, J., Javornik, B., and Thomma, B. P. H. J. 2017. Broad taxonomic characterization of Verticillium wilt resistance genes reveals an ancient origin of the tomato Vel immune receptor. Mol. Plant Pathol. 18:195-209.

Stamova, L. 2005. Resistance to Verticillium dahliae race 2 and its introgression into processing tomato cultivars. Acta Hortic. 695:257-262.

Steyn, W. J., Wand, S. J. E., Holcroft, D. M., and Jacobs, G. 2002. Anthocyanins in vegetative tissues: A proposed unified function in photoprotection. New Phytol. 155:349-361.

Su, W., Tao, R., Liu, W., Yu, C., Yue, Z., He, S., Lavelle, D., Zhang, W., Zhang, L., An, G., Zhang, Y., Hu, Q., Larkin, R. M., Michelmore, R. W., Kuang, H., and Chen, J. 2020. Characterization of four polymorphic genes controlling red leaf colour in lettuce that have undergone disruptive selection since domestication. Plant Biotechnol. J. 18:479-490.

Subbarao, K. V., Davis, R. M., Gilbertson, R. L., and Raid, R. N. 2017. Compendium of Lettuce Diseases and Pests. 2nd ed. American Phytopathological Society, St. Paul, MN.

Treutter, D. 2006. Significance of flavonoids in plant resistance: A review. Environ. Chem. Lett. 4:147-157.

Truco, M. J., Ashrafi, H., Kozik, A., Van Leeuwen, H., Bowers, J., Wo, S. R. C., Stoffel, K., Xu, H., Hill, T., Van Deynze, A., and Michelmore, R. W. 2013. An ultra-high-density, transcript-based, genetic map of lettuce. G3 (Bethesda) 3:617-631.
Usami, T., Momma, N., Kikuchi, S., Watanabe, H., Hayashi, A., Mizukawa, M., Yoshino, K., and Ohmori, Y. 2017. Race 2 of Verticillium dahliae infecting tomato in Japan can be split into two races with differential pathogenicity on resistant rootstocks. Plant Pathol. 66:230-238.

Vallad, G. E., Qin, Q.M., Grube, R., Hayes, R. J., and Subbarao, K. V. 2006. Characterization of race-specific interactions among isolates of Verticillium dahliae pathogenic on lettuce. Phytopathology 96:1380-1387.

Veronese, P., Narasimhan, M. L., Stevenson, R. A., Zhu, J.-K., Weller, S. C., Subbarao, K. V., and Bressan, R. A. 2003. Identification of a locus controlling Verticillium disease symptom response in Arabidopsis thaliana. Plant J. 35:574-587.

Vining, K., and Davis, T. 2009. Isolation of a Ve homolog, $m V e 1$, and its relationship to Verticillium wilt resistance in Mentha longifolia (L.) Huds. Mol. Genet. Genom. 282:173-184.

Wang, D., Zhang, D. D., Usami, T., Liu, L., Yang, L., Huang, J.-Q., Song, J., Li, R., Kong, Z.-Q. Li, J.-J., Wang, J., Klosterman, S. J., Subbarao, K. V., Dai, X.-F., and Chen, J.-Y. 2021. Functional genomics and comparative lineage-specific region analyses reveals novel insights into race divergence in Verticillium dahliae. Microbiol. Spectr. 9:e0111821.

Winkel-Shirley, B. 2002. Biosynthesis of flavonoids and effects of stress. Curr. Opin. Plant Biol. 5:218-223.

Wu, T. D., and Nacu, S. 2010. Fast and SNP-tolerant detection of complex variants and splicing in short reads. Bioinformatics 26:873-881.

Wu, Y., Bhat, P. R., Close, T. J., and Lonardi, S. 2008. Efficient and accurate construction of genetic linkage maps from the minimum spanning tree of a graph. PLoS Genet. 4:e1000212.

Zhang, L., Su, W., Tao, R., Zhang, W., Chen, J., Wu, P., Yan, C., Jia, Y., Larkin, R. M., Lavelle, D., Truco, M. J., Chin-Wo, S. R., Michelmore, R. W., and Kuang. H. 2017. RNA sequencing provides insights into the evolution of lettuce and the regulation of flavonoid biosynthesis. Nat. Commun. $8: 2264$.

Zhang, Y. Z., Xu, S. Z., Cheng, Y. W., Ya, H. Y., and Han, J. M. 2016. Transcriptome analysis and anthocyanin-related genes in red leaf lettuce. Genet. Mol. Res. 15: gmr.15017023. 